\title{
THE EVALUATION OF THE GOVERNMENT DRAFT LOBBYING ACT IN THE CZECH REPUBLIC BEYOND THE FRAMEWORK OF RIA
}

\section{Pavla Bednářová}

1 Technical University of Liberec, Faculty of Economics, Department of Economics, Czech Republic, ORCID: 00000002-5397-4488, pavla.bednarova@tul.cz.

\begin{abstract}
On July 30, 2019 a draft Lobbying Act was approved by the government of the Czech Republic, which reflects growing tendencies to adopt at least minimum normative standards in this area. The aim of the article is to evaluate the lobbying regulatory system in the draft Lobbying Act and its comparison with regulation models in selected European countries through a quantitative cost-benefit analysis. To evaluate the regulatory system from the viewpoint of strength and transparency rate, the specialized Hired Guns methodology (CPI Index) is used. Costs which are needed to achieve, maintain and control a lobbying regulatory system are quantified by means of a methodology by Krsmanovic (CII Index). The CPI Index together with the Cll Index (the Ninefold theory) provides comprehensive and robust assessment of specific regulatory models, but also improves comparative assessment of lobbying regulations in different jurisdictions of selected countries. The current situation in the Czech Republic can be characterized as the existence of non-transparent lobbying. The regulatory system represents a lowly regulated system $(C P I=0)$ / lowly burdensome system $(\mathrm{Cll}=0)$. The regulatory system in the government draft Lobbying Act intended to be achieved corresponds to the definition of a medium regulated system $\left(\mathrm{CPI}=34^{*}\right) /$ medium burdensome system $\left(\mathrm{Cll}=35^{*}\right)$. When compared with selected EU countries - Slovakia, Poland, Hungary, Slovenia, Austria, it can be concluded that the proposed regulatory system meets the standard minimum regulation requirements related to lobbying regulation. It is the first evaluation of the lobbying regulatory system in the Czech Republic and in all other cases it is the first and completely unique use of the evaluation of costs connected with lobbying regulation.
\end{abstract}

Keywords: Lobbying, transparency, regulatory system, regulatory impact assessment, cost benefit analysis.

JEL Classification: F55, D72, P51.

APA Style Citation: Bednářová, P. (2020). The Evaluation of the Government Draft Lobbying Act in the Czech Republic beyond the Framework of RIA. E\&M Economics and Management, 23(2), 33-47. https://doi.org/10.15240/tul/001/2020-2-003

\section{Introduction}

On July 30, 2019, the government of the Czech Republic passed a draft Lobbying Act which was drawn up in accordance with the current Program Declaration of the Government of the Czech Republic, the Government Plan of Legislative Works for 2018 and Government Resolution No. 114 of 21st February 2018, approving the material proposal of the
Lobbying Act. According to the Government's Concept of the Fight Against Corruption for the years 2018 to 2022 (Government of the Czech Republic, 2018) "the intention of the government is to enable the public access to the information about the contact of politicians and high officials with lobbyists and at the same time relieve legitimate lobbying from negative connotations with which it is perceived by the 
public". The aim of the article is to evaluate the lobbying regulation system in the draft Lobbying Act in the Czech Republic and to compare it with regulation models in selected European countries. A partial aim is to complement the assessment included in the Final Report on Regulatory Impact Assessment with a quantitative cost-benefit analysis by means of Ninefold theory.

According to the Transparency International CR (2015), lobbying is an integral part of healthy democracy, closely linked to universal values such as freedom of expression or the right to address the institutions and bodies. At the same time, it defines lobbying as: "any direct or indirect communication with public government officials and with politicians with the aim to influence decision making in the public sphere, performed by any organized group or in its interest". In the recommendation by the Council of Europe (2017), lobbying is defined in the following way: "Lobbying is the enforcement of certain interests by means of communicating with public authorities as part of structured and organized activities with the aim to influence decision-making processes." OECD (2009a) in their first report on lobbying state: "Lobbying is specific effort to influence public decision making either by means of pressure to make changes in current policies or to prevent such changes. Public decision making is an activity a civil servant at any level of public administration who makes decision on any aspects of a policy, measure or the implementation of such a policy is involved in." A definition which is often considered as the most precise is that by Graziano (2001, p. 248): "Lobbying is a specialised and professional representation of interests by means of a wide variety of tools which in principle eliminates a corruptive change of services. It is by its nature very different from a general nonspecialised representation provided by elected representatives. As a representative of particular interests, a lobbyist provides information and technically-professional expertise which can be useful and sometimes decisive for defining legislative and administrative regulation." Laboutková and Žák (2010) delimited the basic attributes of lobbying when "lobbying is first of all focused on advancing interests, it is indispensable source information and the biggest problem is to distinguish lobbying from corruption".
In modern democracy, lobbying is desirable for society as it enables various lobbies to participate in the creation and implementation of decisions and policies and it enables them to present their opinions (Berg \& Freund, 2015). At the same time, lobbying is an information channel by means of which public authorities are better informed about relevant facts. Affecting representatives of the public power with the aim to influence their decisions is, unfortunately, not always transparent and according to clear rules, which brings the risk of the public interests being manipulated in favour of hidden partial interests. According to an international survey (Transparency International, 2013a), nontransparent lobbying is considered one of the main corruption risks which Europe faces. Six out of ten Europeans consider their government in the country considerably influenced or even controlled by hidden interests, which is also confirmed by a Transparency International report of 2015 (Transparency International, 2015). Strengthening the transparency of the legislation and decision making process helps to reveal the influence and the relations between lobbyists and lobbies on the one hand and public entities on the other hand, which should contribute to the reduction of negative impact often connected with lobbying, such as corruption, conflict of interests, protection and clientelism. Bigger openness and transparency in formulation, development and decision making about public policies is however considered crucial for ensuring more efficient public administration. A survey among European politicians and officers (BursonMarsteller, 2013) suggests that $89 \%$ of them agree that ethical and transparent lobbying is beneficial for policy development. According to OECD (2013), creating limits for transparent lobbying is crucial for the integrity of the public decision-making process.

Setting up sufficient, efficient and enforceable lobbying regulation represents a very difficult task for legislators. One of the reasons is the extent of lobbying, or of all the activities which can be considered lobbying. There are a number of options how to set up the regulation - from purely non-legislative, such as an ethics code or public diaries, through gift regulations and lobbyist register, including meeting reporting and the so called legislative footprint to regulation by means of the law which can provide legal framework for the 
individual tools and combine them in different ways. An important reason for improving the tools for lobbying transparency increase is the dynamics of lobbying regulation activity, especially in Europe. Laboutková and Vymětal (2018) offered a methodological proposal for evaluating transparency of lobbying and created an innovative catalogue of lobbying transparency where the transparency in lobbying is conceptualized in broader environment as an alternative to current forms of evaluating transparency in lobbying. The catalogue contains four main categories: lobbyists, targets of lobbying, sunshine principles and monitoring and sanctioning. Regulation can be supportive of market transactions and may result in significant economic, social and environmental benefits. At the same time, illdesigned regulation can have appreciable economic costs, leading to the concept of the "regulatory burden". According to Stacey (2011), "The question of lobbying exceeds the scope of a single act." The combination of rules for political party funding, disclosing the property and income of individual officers and public officials, bigger transparency and personal responsibility when awarding public contracts and within the legislation process, bigger responsibility and transparency of businesses and associations, and also public access to information for anti-corruption organizations, media and the public is the way to effectively prevent the abuse of lobbying. To achieve this, mainly a higher level of civic responsibility of all the above-mentioned process participants is essential.

\section{Literature Review and Methods of the Research}

A standard tool for the assessment of lobbying regulation impact in developed European countries is the Regulatory Impact Assessment (RIA). The aim of RIA is to determine the best option to achieve the objective of a rulemaking activity while minimising potential negative impacts (EASA, 2011). The economic rationale for the use of RIAderives from its expected impact increasing the effectiveness and efficiency of regulatory interventions and thus economic welfare (OECD, 2009b). RIA is a comparative process; it is based on determining the underlying regulatory objectives sought and identifying all the policy interventions that are capable of achieving them. As a methodology,
Cost-Benefit Analyses represents "the best practice" for RIA. According to Hwang (2016, p. 76) they are "a benefit and cost defined in terms of change of human welfare or utility and are measured by individuals' willingnessto-pay for a benefit and willingness-to-accept for a cost". Because it is based on quantifying benefits and costs in monetary terms and comparing them over a suitable period of time, it provides a strong basis for comparing alternatives and for guiding decision-makers on the likely implications of different options. It is very common in RIA to find out that important benefits and costs cannot be quantified (OECD, 2014). However, if the CBA approach is used in such cases, a "partial" CBA can be generated. This can still be very useful for decision-makers as it narrows the range of issues that must be dealt with through a more subjective, qualitative analysis. Thus, developing even an incomplete CBA can greatly improve decision-making. Even where it is able to quantify relatively few costs (or benefits), using CBA's systematic approach to try to ensure that all benefits and costs have been identified and assessed will help to improve the quality of advice provided to decision-makers. In the RIA world, costs are usually addressed differently depending on various factors such as the availability of data, relevance and scope of regulation, the size of the market affected, etc. The term "regulatory costs" as used by the OECD (2014) embraces all the costs attributable to the adoption of a regulatory requirement, whether direct or indirect in nature and whether borne by business, consumers, government and its respective authorities (i.e. taxpayers) or other groups. The problem with application of the cost-benefit aspects, when it comes to lobbying, comes from the nature of benefits associated with lobbying regulation (Krsmanovic, 2014). Benefits associated with the regulation of lobbying could be summarized under the concepts of transparency, accountability and deliberative democracy. All three elements represent non-economic benefits, and thus, they are very hard to directly assess and measure in monetary terms. This is pretty much the case with the regulation of lobbying, where societies tend to regulate lobbying almost exclusively driven by non-economic reasons. According to the OECD (2002, p. 47), “...RIA's most important contribution to the quality of decisions is not the precision of the calculations 
used, but the action of analysing questioning, understanding real world impacts and exploring assumptions."

\subsection{Methods to Measure Benefits from Lobbying Regulation}

The qualitative and quantitative evaluation of lobbying regulation - strictness, restrictiveness, strength or direction, or the development of rules in time - is addressed by rather a small number of scientific publications and professional literature. For a particular quantitative evaluation, usually defined indexes and evaluation scales are used. The first index which was used in the USA for the measurement of the strictness of lobbying regulation was Opheim's Index (1991). This index mainly shows that the strictness of regulation of lobbyists depends on the administrative capacity of lawmakers. The second important index, Brinig et al. Index (1993) was more focused on the evaluation of restrictiveness of lobbyist regulations. The most frequently used tool for the evaluation of lobbying regulation at present is the Index of Newmark (2005), which analyses the development of the strictness of lobbying in time. All three tools were primarily designed for the purpose of lobbyist activity analysis in the USA, both on the federal as well as state level, with the focus on transparency degree measurement. Significant European deeds include a publication by Transparency International (2015), which summarises the outcome of 19 national reports which evaluated the situation in the area of lobbying in 2014 and the attempts at its regulation across Europe. The evaluation methodology was based on internationally recognized standards in the area of lobbying regulation and preventive measures against unfair interference. These standards are set for example by the following OECD (2013) documents The 10 Principles for Transparency and Integrity in Lobbying, and then also by the Venice Commission report (Council of Europe, 2013), Open Governance Scorecard Standards (Transparency International, $2013 \mathrm{~b}$ ), rules prepared by Sunlight Foundation (2013) and standards prepared by Access Info Europe (2013). Based on this foundation, a methodology was prepared containing 65 indicators in three dimensions which are transparency, integrity and equality of access.

An index, which is most often used on a global scale for evaluating and comparing the lobbying regulation, is the CPI (Center for
Public Integrity, 2011). This index is defined on the basis of Opheim's Index and Brinig et al. Index. The CPI enables to evaluate lobbying regulations more deeply and systematically. The results of regulatory rules evaluation refer to transparency and responsibility, and both the indicators can be considered non-monetary benefits of lobbying regulation from the point of view of RIA. The main weakness of the $\mathrm{CPI}$ and also of the previous options from the RIA point of view is the fact that they focus only on the component of strength which can be connected with the benefits of lobbying rules, but they completely leave out the cost components which are of the same importance for the assessment of the regulation impact. Another limiting factor of the CPI typology is the fact that it is not able to completely reflect the specific character of the regulation by means of soft law and focuses only on the rules structure and not on the real level of regulation observance and enforcement. The basis of the CPI methodology selected is formed by a thorough qualitative analysis of relevant regulatory documents. The quantitative part of the research resides in the division of 48 questions in total into eight key areas: definition of lobbyists, individual registration, individual spending disclosure, employer spending disclosure, electronic filling, public access, enforcement and revolving door provision. The individual answers are given specific numerical values (point score) and the maximum attainable number of points is 100 . The CPI methodology generally assumes that the higher the point score of a system is, the closer it gets to the ideal of the full transparency, public access and responsibility. At the same time, the authors emphasise that a "high" CPI score does not need to mean a better regulatory solution and vice versa. On the basis of the evaluation of individual jurisdictions in the area of lobbying regulation, a classification was introduced into the original methodology including the following levels: satisfactory (70 points and more), borderline (60-69 points) and unsatisfactory (under 60 points). Chari, Murphy and Hogan (2011, p. 29) followed up the original concept by creating a "threefold classification" typology according to the point score (strictness/strength) where systems with low lobbying regulation achieve 1-29 points, systems with medium regulation $30-59$ points and a highly regulated systems 60 points and more. They also tried to define the main features 
of the individual theoretical types and describe typical trends in lobbying regulation with impact on transparency and responsibility. Chari, Murphy and Hogan (2011, pp. 25-26) published the results of lobbying regulation evaluation from 2010. On the basis of the point evaluation, in 2010 Hungary (CPI $=45$ points) and Austria ( $\mathrm{CPI}=33$ points) belonged among systems with medium lobbying regulation intensity, Poland $(\mathrm{CPI}=27$ points) ranked among countries with a low lobbying regulation system. Only the US with CPI of 62 points was a country with a high lobbying system regulation. Moderately regulated systems of lobbying in 2010 operated in Canada (CPI = 50 points), Lithuania (CPI $=44$ points) and Slovenia ( $\mathrm{CPI}=35$ points). Poland $(\mathrm{CPI}=27$ points), France (CPI $=19$ points $)$ and Germany ( $\mathrm{CPI}=17$ points) showed a low level of lobbying regulation under the CPI systems.

\subsection{Methods to Measure Costs of Lobbying Regulation}

Regulatory rules themselves create costs as a result of negotiation and information activities which the subjects of regulation as well as executors of regulatory measures incur. Apart from these direct and relatively easily measurable costs, also other costs are related to lobbying regulation which a company incurs as a result of changes in rules in lobbyist activities, such as costs related to the increased competition between lobbyists as a result of increased transparency (Denter, Morgan, \& Sisak, 2011). Current scientific literature brings only one original methodology focused on the quantification of costs connected with lobbying regulation, and it is a methodology defined in Krsmanovic (2014) A Law and Economics Analysis of Lobbying Regulation: Towards an optimal structure through the Cost Indicator Index. The main principle of this methodology is the definition of the CII (Cost-Indicator Index), which was created in combination with the CPI and together they can be used to evaluate the benefits and costs of lobbying regulation. The CIl thus respects the RIA methodology, CPI methodology and also the methodology of the Threefold theory and it is thus suitable for the analysis of regulatory measures within the legislation of individual countries and, at the same time, it represents a tool for ex-ante and ex-post evaluation of lobbying regulation. Fig. 1 provides an overview of the Cll methodology structure, its pillars (left side) and sources (right side).

The Cost Indicator Index Cll consists of 47 individual questions (Krsmanovic, 2014), where questions 1-26 are related to the burden imposed on the private sector and questions 27-47 are related to the burden imposed

\section{Fig. 1: Cll methodology structure}
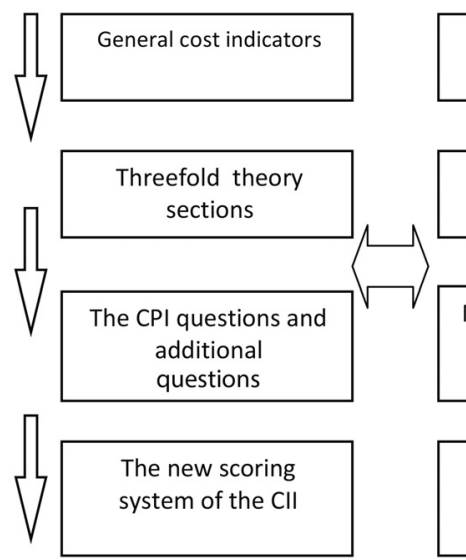

Theory on classification of lobbying regulation

Methodology for assessment of "strength" of lobbying rules - Hired Guns Assessment methodology

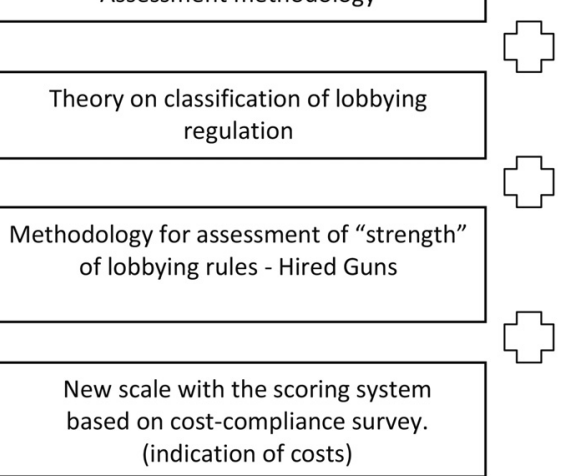


on the public sector. The reached values of the index are in the range $0-288$ points. The depth of the analysis that the Cll provides is in compliance with the depth of the analysis provided by the CPI method, and if fast and easily comparable use of both the scales is to be ensured, it is necessary to unite the scale at the interval 0-100 points, which can be achieved by a simple division of the Cll value by 2.88 . If subsequently the same methodology of the CII Threefold theory is applied to CII, it is possible to divide the systems which qualitatively and quantitatively classify lobbyist regulations into systems with a low regulatory burden ( $\mathrm{Cll}$ in the range of 1-29 points), systems with a medium burden of lobbying regulation (CII value amounting to 30-69 points) and highly burdened systems in terms of costs (CII value in the range $70-100$ points). With regards to the fact that it is desirable to keep the cost burden of a lobbying regulation system as low as possible, lower CII levels represent a better alternative than high Cll scores.

To assess regulatory quality, it is necessary to evaluate two key elements - benefits and costs, which means the interconnection of the Threefold theory of classification of lobbying regulation (based on the $\mathrm{CPI}$ ) and the Cll Threefold theory of classification of lobbying regulation (based on the CII). This interconnection represents a new platform for the qualitative and quantitative evaluation of the adopted acts related to lobbying and of draft acts - The Ninefold theory (Krsmanovic, 2014). On the basis of the Ninefold theory it is possible to structure lobbying regulation systems into nine different types according to their qualitative and quantitative characteristics acquired by the $\mathrm{CPI}$ and $\mathrm{Cll}$ application. On the basis of the assumption that in the case of lobbyist regulation, the society will give preference to the biggest possible transparency and responsibility while attempting to minimize costs, then regulatory measures which have higher benefits than costs (CPI is bigger than $\mathrm{CII}$ ) can be considered good. Medium categories when the $\mathrm{CPI}$ and $\mathrm{Cll}$ values are in the same intervals represent acceptable regulation systems. Unacceptable options of lobbying regulation are characterised by costs higher than acquired benefits (CPI is smaller than CII). At the same time, the evaluation of costs on the "low, medium and high" level on the basis of the Ninefold theory classification enables to compare different jurisdictions regardless of the monetary expression, which is a significant advantage in comparison with regulation assessment based on RIA. In the comparative analysis of lobbyist regulation, RIA procedures are not commonly applicable because they often differ significantly in the approach to evaluation, in the type of evaluation, its extent, depth and descriptiveness.

\section{Research Results}

To evaluate a regulatory system from the viewpoint of strength which it has, and the transparency rate which it generates, the specialized Hired Guns methodology (CPI Index) is used. Costs which are needed to achieve, maintain and control a lobbying regulatory system are quantified by means of a methodology by Krsmanovic (CII Index). The CII Index together with the CPI Index provide comprehensive and robust assessment of specific regulatory models - the current state in the Czech Republic and the governmental draft Lobbying Act, but also improve comparative assessment of lobbying regulations in selected European countries - Slovakia, Hungary, Poland, Slovenia and Austria. The results are achieved on the basis of ex post evaluation of their current laws or rules of lobbying regulation. The Ninefold theory enables to compare these different jurisdictions, which is a significant advantage in comparison with regulation evaluation based on RIA.

\subsection{Assessment of the Current Situation in Lobbying Regulation in the Czech Republic by Means of the Ninefold Theory}

In the Czech Republic, with regards to its historical development, lobbying does not have long tradition - it started to develop in the context of democratic transformation after 1989. Despite attempts at its regulation, which would contribute to higher quality and professionalism of lobbying, the Czech Republic still belong among countries where there is no regulation in this area. The current state in the Czech Republic can be characterized as a situation of the existence of non-transparent lobbying without adopting any measures to increase decision-making and legislative process transparency. The risk arising from retaining the non-transparency 
state is negative impact on the creation of public policies and adoption of decisions from the view point of potential advancing of hidden interests or giving preference to certain interests over others, and also on the public whose confidence in these processes decrease. Public decisions or activities of public institutions then lose their legitimacy. Other risks include democracy erosion, decrease of citizens' confidence in politics, political parties and institutions. It can be assumed that the problems of the current condition will become worse and deeper, namely (Government Office of the Czech Republic, 2019): the lingering low transparency of the legislation process which will lead to gradually deteriorating quality of legal regulations, pressure coming from interests groups and aiming at reaching such legislation which would be advantageous mainly for the groups themselves, consequently to this, the quality of business environment will deteriorate and also the attractiveness of the CR not only for foreign investors but also for Czech companies, low level of decision-making processes transparency (strategic planning, awarding tenders, etc.) in public administration and low level of control over the influence on decision making of entities in public power. The costs and benefits of the zero option can be quantified only with difficulty and only by means of expert estimation. Direct costs would arise in the case of unsuccessful international arbitrations, in the case of reduced tax revenue caused by the outflow of businesses form the country, or if small businesses become more difficult to run or if the rating and evaluation of the country by the World Bank and the International Monetary Fund worsened, which would lead to the reduction of international investments (Bednářová, 2018a). Direct benefits associated with maintaining the current state are the absence of regulatory costs incurred by the addressees of the regulation and the public sector and preservation of the existing administration. Indirect benefits can be seen in not interfering with the private sector of individuals in the form of personal data disclosure (Bednářová, 2018b). As there is no regulation, it is not possible to quantitatively evaluate either benefits or costs. The current situation in lobbying regulation in the $\mathrm{CR}$ thus represents a Lowly regulated system $(\mathrm{CPI}=0)$ / lowly burdensome system $(\mathrm{Cll}=0)$.
The need of institutional lobbying regulation results from the increase in the complexity of governing leading to the growing significance of expert opinion in decision-making processes. Since 2004, four unsuccessful attempts at lobbying regulation have been recorded, out of which one was a draft ethics code and three draft acts while the last draft act failed to be passed by the Parliament of the CR in 2012. The current draft Lobbying Act (Government Office of the Czech Republic, 2019) was approved by the government on July 30, 2019 and as part of the legislation process it continues to the Parliament. If the Parliament passes the draft act, it is expected to come into effect on January 1, 2021 (Government Office of the Czech Republic, 2019, §18). The Czech Republic is thus supposed to become the eighth country in the EU which will introduce legal lobbying regulation, which is already in force in Ireland, the UK, France, Austria, Slovenia, Poland and Lithuania. The EU law does not regulate lobbying on a national level, it is a legal area which is fully in competence of member states.

According to the current initiative, the aim of the draft lobbying regulation is mainly to "set transparent rules for lobbying and to define lobbying as a standard activity within the legislation and decision-making process on a central level". The submitted draft Lobbying Act defines lobbying and sets its scope both in a positive and negative way. It further defines the circle of lobbyists, the lobbied, lobbying means and the powers of public authorities in the field of lobbying. A register of lobbyists and the lobbied is being established and the procedures of entering and deleting from the register are being set. In the draft act it further says that lobbying regulation needs to be approached rationally in such a way that it will represent mainly: "cost-effective and legislatively adequate solution corresponding to the set intention" (Government Office of the Czech Republic, 2019).

The government proposal contains a Final Report on RIA related the draft Lobbying Act and to the draft act amending certain laws in connection with the adoption of the Lobbying Act (Government Office of the Czech Republic, 2019). The Report contains the assessment of the regulation proposal impact on the state budget and other public budgets, on international competitiveness, on business 
environment, on territorial self-governing units. It further assesses social impact, impact on consumers, impact on the environment, impact in relation to the ban of discrimination and gender equality, impact on the performance of the State Statistical Service, impact on the security or defence of the State, and considers corruption risks. In the Report, the authors assessed possible regulation alternatives which differ from each other regarding the combination of the individual tools and the scope, or the effect of the potential rules. The alternative being assessed is zero Option I (existing condition of the unregulated lobbying without changes), Option II (non-legislation option which includes the creation and adoption of an ethics code for members of parliament, senators and government members), Option III (comprising legislation measures supplemented by non-legislation measures) and Option IV (a wide option including lobbying in its common definition including the level of municipality and regional authorities). In this case, RIA assessment method was mainly a qualitative analysis, because it is difficult to quantify expected benefits (e.g. a positive signal towards the society about the effort to set ethical standard, increase in transparency after a public diary is implemented, increase in transparency of lobbying activities, introduction of a legislation footprint as a standard in the legislation process $(\mathrm{CR})$, but also the majority of the related costs (e.g. high demands on public officials' moral integrity, intervention into the privacy of natural persons in the form of disclosure of their data in the registry of lobbyists, formality and a low information value of the data included in the legislation footprint, difficulty to foresee the efficiency of government and parliament measures). Predictable quantifiable costs thus include mainly costs of the establishment and operation of a register of lobbyists, costs of the public sector related to the supervision over the compliance with the regulation, the increase in financial and administrative costs of entities entered into the register, the increase in administrative costs of public officials when collecting and entering data representing the basis for a legislation footprint, or cost of the establishment of a special section in the Notification register under the Conflict of Interest Act. The Government Office of the Czech Republic (RIA, 2019) concludes that: "according to the assessment of benefits and costs, Option III is assessed and a solution which meets the purpose and meaning of the regulation being prepared while maintaining an acceptable level of administrative and financial requirements".

\subsection{Assessment of the Draft Lobbying Act by Means of the Ninefold Theory}

In the proposed regulation from the RIA point of view, benefits are assessed only qualitatively. When the Hirend Gunds method for the assessment of the proposed regulation was applied, the CPI reached 34 points, as illustrated in Tab. 1. In Tab. 1, only the questions where answers with a non-zero score were detected are included. Questions where there were zero-score answers are not included (for a complete CPI methodology see CPI, 2011).

Tab. 1:

The assessment of the regulation system of the Lobbying Act according to the CPI methodology - Part 1

\begin{tabular}{|c|c|}
\hline CPI (draft Lobbying Act) & $\mathbf{C Z}^{*}$ \\
\hline \multicolumn{2}{|l|}{ Definition of a lobbyist } \\
\hline $\begin{array}{l}\text { 1. In addition to legislative lobbyists, does the definition recognize executive } \\
\text { branch lobbyists? No - } 0 \text { points; Yes }-3 \text { points }\end{array}$ & $3[\S 2(1), \S 3]$ \\
\hline $\begin{array}{l}\text { 2. How much does an individual have to make/spend to qualify as a lobbyist or to } \\
\text { prompt registration as a lobbyist, according to the definition? More than } \$ 500 \\
-0 \text { points; More than } \$ 100-1 \text { point; More than } \$ 50-2 \text { points; } \$ 50 \text { or less }-3 \\
\text { points; Lobbyists qualify and must register no matter how much money made/ } \\
\text { spent - } 4 \text { points }\end{array}$ & $4[\S 6(3)]$ \\
\hline \multicolumn{2}{|l|}{ Individual registration } \\
\hline 3. Is a lobbyist required to file a registration form? No -0 points; Yes -3 points & $3[\S 6(1)]$ \\
\hline
\end{tabular}




\section{CPI (draft Lobbying Act)}

4. How many days can lobbying take place before registration is required? 16 or more days -0 points; 11 to 15 days -1 point; 6 to 10 days -2 points; 1 to 5 $4[\S 6(2)]$ days -3 points; 0 days -4 points

5 . Is subject matter or bill number to be addressed by a lobbyist required on registration forms? No bill number/subject matter required -0 points; Subject matter only required -1 point; Bill number required -3 points

7. Within how many days must a lobbyist notify the oversight agency of changes in registration? 16 -or more days -0 points; $11-15$ days -1 point; $6-10$ days -2 points; $1-5$ days -3 points; 0 days -4 points

9. Is a lobbyist required to identify by name each employer on the registration form? No - 0 points; Yes - 1point

\section{Individual spending disclosure}

25. Is a lobbyist who has done no spending during a filing period required to make a report of no activity? No -0 points; Yes -1 point

\section{Employer spending disclosure}

\section{Electronic filling}

28. Does the oversight agency provide lobbyists/employers with online registration? No - 0 points; Yes - 1 point

30. Does the oversight agency provide training about how to file registrations/ spending reports electronically? No -0 points; Yes -1 point

\section{Public access}

31. Location/format of registrations or active lobbyist directory: Photocopies from office only - 1 point; PDF or image files on the Web - 2 points; Searchable database on the Web -3 points; Downloadable files/database -4 points

34. Are sample registration forms/spending reports available on the Web? No - 0 points; Yes -1 point

38. How often are lobby lists updated? Semi-annually or less often - 1 point; Monthly -2 points; Weekly -3 points; Daily -4 points

\section{Enforcement}

39. Does the state have statutory auditing authority? No -0 points; Yes -2 points

40 . Does the state agency conduct mandatory reviews or audits? No - 0 points; Yes -2 points

41. Is there a statutory penalty for late filing of lobby registration form? No -0 points; Yes -1 point

44. Is there a statutory penalty for incomplete filing of a lobby registration form? No - 0 points; Yes -1 point

\section{Revolving door provision}

Total score:

Using the CPI, it is possible to compare the proposed regulatory system with the current condition of non-regulated lobbying by means of eight defined key areas. In the Czech
Republic, there has not been a legally defined concept of lobbyist so far. In the draft Lobbying Act (Government Office of the Czech Republic, $2019, \S 3)$ a lobbyist is defined as "a person of 
law and integrity who makes a declaration that he/she intends to lob in the interest of a third party or in his/her own interest". Lobbyists have a duty to register regardless of the amount they have to make/spend. Under the draft lobbying act, lobbyists will be obliged to fill in a registration form within ten days after they have commenced their activities at the latest. The subject matter and bill number by a lobbyist must be included in the registration forms. The disclosure of individual expenditures is not included in the draft lobbying act. The obligation to disclose a report on expenditures or to disclose remuneration/salary is not considered. At the same time, lobbyists have a duty to report no activity. The disclosure of the employer's expenditures is not included in the draft Lobbying Act. Electronic filing will be enabled by means of on-line registration, including training on filling in the registration electronically. Downloadable files are a public access option in the draft act. At the same time, a list of lobbyists will be updated every month. The supervision over the compliance with duties under the Lobbying Act (Government Office of the Czech Republic, 2019, §5) will be performed by the Office for the Surveillance of the Political Parties and Political Movements, which will be authorised to perform surveillance, consider offences, or impose sanctions. The draft act in the Czech Republic does not address revolving door provisions either. In the new regulation of lobbying, what could be criticised is the relatively non-standard definition of lobbying, lobbyists and the lobbied as well as a low level of control over the data entered into the Register. A space for the tightening of the regulation could be found also in the increase in the scope of the information required about the entities' lobbying activities themselves or about their funding.

The Final RIA report attached to the draft Lobbying Act contains qualitative assessment of cost related to Option III. Quantitative assessment of costs is limited to the quantification of "the costs on the establishment of a register of lobbyists and the lobbied, which in this Option can be expected to amount to approximately CZK $500,000-700,000$ without VAT ... and the costs of the operation of the register, including personnel costs, which will amount approximately to 1 million Czech crowns a year". When the costs needed to be spent in relation to the regulation in the case of proposed Option III were assessed by means of the Cll methodology, the index amounted to 35 points. Specific questions which are connected with a non-zero assessment of an answer are included in Tab. 2 (questions with a zero assessment of the answer are not included, for complete methodology Cll see Krsmanovic, 2014).

The level of regulation which should be achieved on the basis of the draft Lobbying

Tab. 2:

The assessment of the regulatory system of the Lobbying Act according to the Cll methodology - Part 1

$$
\text { CII (draft Lobbying Act) }
$$

\section{Definition of a lobbyist}

1. How much does an individual have to make/spend to qualify as a lobbyist or to prompt registration as a lobbyist, according to the definition? Qualification threshold: More than $\$ 10,000$ made -4 points; Qualification threshold: More than $\$ 2,500$ made -6 points; Qualification threshold: regardless the amount made -7 points

\section{Individual registration}

2. Is a lobbyist required to file a registration form? No -0 points; Yes -5 points

3. How many days can lobbying take place before registration is required? 6 months or more -4 points; Up to a month -5 points; Up to 3 days -5 points

4. Is subject matter or bill number to be addressed by a lobbyist required on registration forms? No bill number/subject matter required -0 points; Subject matter only required -4 points; Bill number required -5 points

5. How often is registration by a lobbyist required? Once only -2 points; Every two years -4 points; Annually or more often -4 points 


\section{CII (draft Lobbying Act)}

6. Within how many days must a lobbyist notify the oversight agency of changes in registration? 6 months or more -4 points; Up to a month -5 points; Up to 3 days -5 points

8 . Is a lobbyist required to identify by name each employer on the registration form?

No -0 points; Yes -6 points

Individual spending disclosure

24. Is a lobbyist who has done no spending during a filing period required to make a report of no activity? No -0 points; Yes -4 points

\section{Employer spending disclosure}

\section{Electronic filling}

27. Does oversight agency provide lobbyists/employers with online registration? No -0 points; Yes -4 points

29. Does oversight agency provide training about how to file registrations/ spending reports electronically? No -0 points; Yes -4 points

Public access

30. Location/format of registrations or active lobbyist directory: Photocopies from office only -6 points; PDF or image files on the Web -3 points; Searchable database on the Web -4 points; Downloadable files/database -4 points

33. Are sample registration forms/spending reports available the Web? No - 0 points; Yes -3 points

37. How often are lobby lists updated? Annually or less often -6 points; Monthly 7 points; Weekly - 7 points

38. In addition to legislative lobbyists, does the definition recognize executive branch lobbyists? No -0 points; Yes -3 points

\section{Enforcement}

40. Does the state have statutory auditing authority? No -0 points; Yes -7 points

41. Does oversight agency conducts mandatory reviews or audits? No - 0 points; Yes -8 points

42. Is there a statutory penalty for late filing of lobby registration form? No -0 points; Yes -8 points

44. Is there a statutory penalty for incomplete filling of a lobby registration form? No - 0 points; Yes -8 points

46. Structure/type of oversight agency? Already existing administrative unit with attributed tasks of enforcement of lobbying rules -6 points; Entirely new administrative agency -8 points

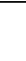


Fig. 2: The assessment of the regulation systems according to the Ninefold theory

\begin{tabular}{|c|c|c|c|}
\hline $\begin{array}{l}\text { Highly regulated } \\
\text { Systems }(60-100)\end{array}$ & High - Low & High - Medium & High - High \\
\hline $\begin{array}{l}\text { Medium regulated } \\
\text { Systems }(30-59)\end{array}$ & Medium - Low & $\begin{array}{l}\text { Medium - Medium } \\
\text { Czech Republic* }\left(34^{*} / 35^{\star}\right) \\
\text { Austria }(38 / 49) \\
\text { Poland }(31 / 34) \\
\text { Slovenia }(41 / 44)\end{array}$ & Medium - High \\
\hline $\begin{array}{l}\text { Lowly regulated } \\
\text { Systems (0-29) }\end{array}$ & $\begin{array}{l}\text { Low - Low } \\
\text { Czech Republic }(0 / 0) \\
\text { Hungary }(0 / 0) \\
\text { Slovakia }(6 / 10)\end{array}$ & Low - Medium & Low - High \\
\hline CPI & $\begin{array}{l}\text { Lowly burdensome } \\
\text { systems } \\
(0-29)\end{array}$ & $\begin{array}{l}\text { Medium burdensome } \\
\text { Systems } \\
(30-69)\end{array}$ & $\begin{array}{l}\text { Highly burdensome } \\
\text { Systems } \\
(70-100)\end{array}$ \\
\hline
\end{tabular}

Source: own calculation in Laboutková et al. (2020), methodology in Krsmanovic (2014)

The Ninefold theory method can be used to compare regulatory systems in the area of lobbying in selected countries. By means of this method, it is possible to provide evidence whether the government draft Lobbying Act contains sufficient, efficient and feasible measures of lobbying regulation in comparison with selected European countries. Fig. 2 contains regulatory system assessment in Hungary, Slovakia, Austria, Poland and Slovenia. The relevant information for the author's own calculations was received from their national legislation for 2018. In all the cases, it is the first and completely unique use of the evaluation of costs connected with lobbying regulation. Based on the evaluation by Hired Guns method $\mathrm{CPI}$ and Krsmanovic method CII, it can be stated that all the countries fall into the category that represents acceptable regulatory systems, where $\mathrm{CPI}$ and $\mathrm{Cll}$ are at same intervals. Regulatory systems in Hungary and the Slovak Republic can be characterized as lowly regulated and lowly burdensome systems. There are no statutory rules in Hungary $(\mathrm{CPI}=0 / C / l=0)$, which is reflected in the zero $\mathrm{CPI}$ and $\mathrm{Cll}$ indexes. Lobbying regulation was abandoned by the government and replaced by Act CXXXI of 2010 on Public Participation in Developing Legislation, which came into force in January 2011 (EPRS, 2016). Related rules in The Government decree on the system of integrity management within public administration issued in 2013 , obliges public servants to ask prior permission from their superior to meet lobbyists and also to report back on the contacts or outcome of meetings. There is no mechanism in place targeting monitoring of the implementation of these obligations. There are no statutory rules in the Slovak Republic $(\mathrm{CPI}=6 / \mathrm{Cll}=10)$; two draft bills on lobbying were submitted, however, neither of them was approved. The issues of revolving door and monitoring and sanctions are partially regulated. The other seven key areas included in the CPI index are not regulated by legislation. Austria has adopted legal regulation of lobbying when the Austrian Bundesrat passed "Transparenzpaket" (Transparency package) on June 2012, which took effect on January 2013. This package comprises a series of transparency-related laws, among them the so called "LobbyG" regulating lobbying and interest representation and introducing a register (EPRS, 2016). Practically the same level of lobbying benefits as in the Czech Republic* is provided by the Austrian regulatory system $(\mathrm{CPI}=38 / \mathrm{Cll}=49)$, but this level of benefits is achieved by using higher costs which are mainly associated with a higher frequency of lobbying reports and a higher degree of public access and control. The regulatory system in Slovenia $(\mathrm{CPI}=41 / \mathrm{Cll}=44)$ allows to get most benefits from lobbying regulation out of all the countries in the comparison with a reasonable cost burden. Compared to other countries, the provision and reporting of lobbyists' gifts 
is regulated in Slovenia, fast and open public access to information in the country works. Lobbying activities are regulated in the Integrity and Prevention of Corruption Act (EPRS, 2016). Legislative changes in 2010 and 2011 focused on integrity and prevention of corrupt practices, conflicts of interest, transparency of lobbying, whistleblower protection, public procurement, criminal law provisions and criminal procedure. The Act on Legislative and Regulatory Lobbying in Poland passed by Sejm in July 2005 came into force in March 2006 after a number of corruption scandals and informal relations between interest groups and public officials. The Act promotes transparency in the law-making process and was amended in 2011 (EPRS, 2016). The regulatory system in Poland $(\mathrm{CPI}=31 / \mathrm{C} / \mathrm{I}=34)$ is "the weakest" in the countries under comparison, the definition of lobbyist and individual registration are regulated; statutory auditing authority and revolving door provision are functional. Weaknesses can be detected in electronic filling and public access.

\section{Conclusions}

On July 30, 2019 a draft Lobbying Act was approved by the government of the Czech Republic, which reflects growing tendencies to adopt at least minimum normative standards in this area in the EU member countries. The aim of the article was to evaluate the lobbying regulatory system in the draft Lobbying Act in the Czech Republic and its comparison with regulation models in selected European countries. A partial aim was to complement the assessment included in the Final Report on RIA with a quantitative cost-benefit analysis. In the article an empiric-analytic approach was used to which also the used methodology contributes. To evaluate the regulatory system from the viewpoint of strength which it has, and the transparency rate which it generates, the specialized Hired Guns methodology of the Centre for Public Integrity was used, within which the CPI is defined. Based on the achieved score of the CPI, lobbying regulatory systems are perceived as lowly regulated, medium regulated or highly regulated systems. Costs which are needed to achieve, maintain and control a lobbying regulatory system were quantified by means of a methodology by Krsmanovic, the main principle of which is the creation of the CII. Based on the CII score, regulatory systems are divided into lowly burdensome systems, systems with a medium burden of lobbying regulation and highly burdened systems. By means of the mutual combination, a new platform was created used for assessment and mutual comparison of lobbying regulation systems from the viewpoint of a cost-benefit analysis - the Ninefold theory.

The current state in the Czech Republic can be characterized as a situation of the existence of non-transparent lobbying without adopting any measures to increase decision-making and legislative process transparency. The regulatory system represents a lowly regulated system $(\mathrm{CPI}=0)$ /lowly burdensome system $(C l l=0)$. The governmental draft Lobbying Act regulates conditions of lobbying, obligations of lobbyists, the lobbied and lobbying means and the powers of public authorities in the field of lobbying. The draft regulation is in accordance with Option III from the point of view of the Final Regulatory Impact Assessment. The regulatory system intended to be achieved corresponds to the definition of a medium regulated system $\left(\mathrm{CPI}=34^{*}\right) /$ medium burdensome system $\left(C I I=35^{*}\right)$ and it represents a significant improvement in the area of lobbying regulation when compared with the current situation.

When compared with selected EU countries it can be concluded that the proposed regulatory system meets the standard minimum regulation requirements related to lobbying regulation. If the government draft Lobbying Act is passed, the Czech Republic will rank behind Slovenia and Austria, on the same level of regulation as in Poland and will significantly surpass the regulatory systems in Slovakia and Hungary. Regulatory systems in Hungary $(\mathrm{CPI}=0 / \mathrm{Cll}=0)$ and Slovakia $(\mathrm{CPI}=6 / \mathrm{Cl}=10)$ can be characterized as lowly regulated and lowly burdensome systems. There are no statutory rules in both the countries, only the issue of revolving door and monitoring and sanctions are partially regulated in Slovakia. Austria has adopted legal regulation of lobbying in 2012. The Austrian regulatory system $(\mathrm{CPI}=38 / \mathrm{Cl}=49)$ belongs among Medium regulated systems/Medium burdensome systems, as well as lobbying regulatory systems in Slovenia and Poland. The regulatory system in Slovenia $(\mathrm{CPI}=41 / \mathrm{Cll}=44)$ allows to get most benefits from lobbying regulation out of all the countries being compared with a reasonable cost burden. Lobbying activities 
are regulated in the Integrity and Prevention of Corruption Act (EPRS, 2016) that is focused on the integrity and prevention of corrupt practices, conflicts of interest and transparency of lobbying. The Act on Legislative and Regulatory Lobbying in Poland was passed by Sejm in July 2005 after a number of corruption scandals and was amended in 2011. The regulatory system in Poland $(\mathrm{CPI}=31 / \mathrm{Cl}=34)$ is "the weakest" among the countries being compared. All the selected European countries fall into the category that represents acceptable regulatory systems, where $\mathrm{CPI}$ and $\mathrm{Cll}$ are at same intervals. It is the first evaluation of the lobbying regulatory system in the Czech Republic and in all other cases it is the first and completely unique use of the evaluation of costs connected with lobbying regulation.

Acknowledgement: This article is supported by the Czech Science Foundation, project No. GA1608786S "Impact of Transparency of Lobbying on Democratization and lts Consequences".

\section{References}

Access Info Europe. (2013). Standards: Lobbying Transparency via Right to Information Laws. Retrieved January 21, 2018, from https://www.access-info.org/blog/2013/12/12/ lobbying-report/

Bednářová, P. (2018a). How Expensive Transparent Lobbying Is. ACC Journal, 24(2), 7-19. https://doi.org/10.15240/tul/004/2018-2-001

Bednářová, P. (2018b). What Benefits Does Transparent Lobbying Bring. DANUBE: Law and Economics Review, 9(3), 193-205. Retrieved from http://www.eaco.eu/wp-content/ uploads/2018/10/bednarova.pdf

Berg, J., \& Freund, D. (2015). EU Legislative Footprint: What's the real influence of lobbying? Brussels: TI-EU Office.

Brinig, M. F., Holcombe, R. G., \& Schwartzstein, L. (1993). The Regulation of Lobbyists. Public Choice, 77(2), 377-384. https://doi.org/10.1007/BF01047876

Burson-Marsteller. (2013). A Guide to Effective Lobbying in Europe - The View of Policy-Makers. Retrieved March 24, 2019, from https://www.transparency.cz/wp-content/ uploads/Lobbying-in-Europe.pdf

Center for Public Integrity. (2011). Accountability: Waste, Fraud and Abuse: Hired Guns. Methodology. Retrieved November
10, 2018, from http://www.publicintegrity. org/2003/05/15/5914/methodology

Chari, R., Hogan, J., \& Murphy, G. (2011). Report on the Legal Framework for the Regulation of Lobbying in the Council of Europe Member States. Venice Commission. Retrieved November 10, 2018, from https://www.venice.coe.int/webforms/documents/ default.aspx?pdffile=CDL-DEM(2011)002-e

Council of Europe. (2013). Report on the Role of Extra-Institutional Actors in the Democratic System (Lobbying). Strasbourg: Council of Europe Publishing.

Council of Europe. (2017). Legal Regulation of Lobbying Activities in the Context of Public Decision Making. Recommendation CM/ $\operatorname{Rec}(2017) 2$ and explanatory memorandum. Strasbourg: Council of Europe Publishing.

Denter, P., Morgan, J., \& Sisak, D. (2011). 'Where Ignorance is Bliss, 'Tis Folly to Be Wise': Transparency in Contests. http://dx.doi. org/10.2139/ssrn.1836905

EASA. (2011). Regulatory ImpactAssessment (RIA) Methodology. Retrieved March 24, 2019, from https://www.easa.europa.eu/sites/default/ files/dfu/rulemaking-docs-procedures-andwork-instructions-WI.RPRO.00046--RegulatoryImpact-Assessment-(RIA)-Methodology.pdf

EPRS. (2016). Transparency of lobbying in Member States Comparative analysis. Retrieved June 4, 2018, from http://www. europarl.europa.eu/EPRS/Transparency_of_ lobbying_in_Member_States.pdf

Government Office of the Czech Republic. (2018). Vládní koncepce boje s korupcí na léta 2018 až 2022. Retrieved October 19, 2018, from https://korupce.cz/protikorupcni-dokumentyvlady/na-leta-2018-az-2022/

Government Office of the Czech Republic. (2019). Vládní návrh Zákona o lobbování. Retrieved August 15, 2019, from https://apps. odok.cz/veklep-detail?pid=KORNB4B9CNQE

Graziano, L. (2001). Lobbying, Pluralism, and Democracy. Basingstoke: Palgrave.

Hwang, K. (2016). Cost-benefit analysis: its usage and critiques. Journal of Public Affairs, 16(1), 75-80. https://doi.org/10.1002/pa.1565

Krsmanovic, D. (2014). A Law and Economics Analysis of Lobbying Regulation: Towards an optimal structure through the Cost Indicator Index. EDLE - The European Doctorate in Law and Economics programme. Erasmus University Rotterdam. Retrieved April 6, 2018, from http://hdl.handle.net/1765/51601 
Laboutková, Š., \& Žák, M. (2010). Lobbování v Evropské unii a v České republice. Politická ekonomie, 58(5), 579-594. https:// polek.vse.cz/pdfs/pol/2010/05/01.pdf

Laboutková, Š., \& Vymětal, P. (2018). Key Elements of Transparent Lobbying: Relevance of Wider Approach. Public Policy and Administration, 17(2), 165-176. https://doi. org/10.13165/VPA-18-17-2-01

Laboutková, Š., Šimral, V., \& Vymětal, P. (2020). Transparent Lobbying and Democracy. Cham: Palgrave Macmillan. https://doi.org/10.1007/978-3-030-36044-3

Mulcahy, S. (2015). Lobbying in Europe: Hidden Influence, Privileged Access. Berlin: Transparency International.

Newmark, A. J. (2005). Measuring State Legislative Lobbying Regulation 1990-2003. State Politics \& Policy Quarterly, 5(2), 182-191. https://doi.org/10.1177/153244000500500205

OECD. (2002). Regulatory Policies in OECD Countries: From Interventionism to Regulatory Governance. Paris: OECD Publishing. https://doi.org/10.1787/19900481

OECD. (2009a). Lobbyists, Governments and Public Trust, Volume 1: Increasing Transparency through Legislation. Paris: OECD Publishing. https://doi.org/10.1787/9789264073371-en

OECD. (2009b). Regulatory Impact Analysis: A ToolforPolicy Coherence. Paris: OECD Publishing. https://dx.doi.org/10.1787/9789264067110-en

OECD. (2013). Transparency and Integrity in Lobbying. Paris: OECD Publishing. https://www.oecd.org/corruption/ethics/ Lobbying-Brochure.pdf
OECD. (2014). OECD Regulatory Compliance Cost Assessment Guidance. Paris: OECD Publishing. https://dx.doi. org/10.1787/9789264209657-en

Opheim, C. (1991). Explaining the Differences in State Lobby Regulation. Political Research Quarterly, 44(2), 405-421. https://doi.org/10.1177\%2F106591299104400209

Stacey, W. (2011). Transparentní lobbing přesahuje účinnost jediného zákona. In Transparentni lobbying: Jak jej docilit? (Sborník z konference). Senát PČR. Retrieved from https://ies.fsv.cuni.cz/default/file/download/ id/18032

Sunlight Foundation. (2013). Open Data Policy Guidelines. Retrieved January 21, 2018, from http://sunlightfoundation.com/ opendataguidelines

Transparency International. (2013a). Global Corruption Barometer. Retrieved January 21, 2018, from https://www.transparency.org/ gcb2013/report

Transparency International. (2013b). Open Governance Standards. Berlin: Transparency International Secretariat. Retrieved February 16, 2018, from https://knowledgehub. transparency.org/assets/uploads/kproducts/ TI_open_governance_standards.pdf

Transparency International. (2015). Lobbying in Europe: Hidden Influence, Privileged Access. Retrieved June 9, 2018, from https://www.transparency.org/files/content/ feature/2015_LobbyingEurope_Methodology_ EN.pdf 